\title{
SCIDOC
}

\author{
International Journal of Dentistry and Oral Science (IJDOS) \\ ISSN: 2377-8075
}

\section{Prosthetic Re-Treatment Of Failed Fixed Dental Prosthesis Therapy and Its Correlation With Abfraction: A Retrospective Analysis}

Research Article

Rupawat Divya Kamlesh ${ }^{1}$, Vinay ${ }^{2 *}$

${ }^{1}$ Saveetha Dental College and Hospitals, Saveetha Institute of Medical and Technical Sciences, Saveetha University, Chennai, India.

${ }^{2}$ Department of Prosthodontics, Saveetha Dental College and Hospitals, Saveetha Institute of Medical and Technical Sciences, Saveetha University, Chennai, 600077, India.

Abstract

The purpose of this study is to evaluate the prevalence of prosthetic re-treatment of failed fixed dental prosthesis therapy. There is a need to check for any harmful or unbalanced occlusal forces for planning for a fixed dental prosthesis as this may change the material to be used for the prosthesis as well as the treatment protocol. A retrospective study was done in a university based setting. Data of 86000 patients between June 2019 and March 2020 was reviewed from the patients records and analysed. Data of 782 patients with failed fixed dental prosthesis was analysed. Out of these 232 were retreatment cases and the reason for failure of fixed partial prosthesis patients was analysed. The data entered was tabulated and analysed for the prevalence of failure of fixed dental prosthesis and retreatment required due to posterior tooth loss, caries, esthetics, occlusal discrepancy, ceramic chipping and others. Statistical analysis was done using SPSS Software for Windows, version 20.0. It was found that $14 \%$ of the cases had posterior tooth loss, $26 \%$ cases were repeated because of ceramic chipping, $21 \%$ cases came back with dislodgement of the fixed dental prosthesis, $6 \%$ of the cases had caries of the abutment tooth, $15 \%$ cases showed some premature contacts or occlusal discrepancy, $18 \%$ of the cases were repeated because of esthetics. The Chi-square value showed no significant relation between age with respect to abfraction and reasons of failure. Similar results were found with respect to gender. The association between abfraction and failure of fixed dental prosthesis was statistically not significant, however there is an increased rate of ceramic chipping in patients with abfraction. The failure of the fixed dental prosthesis could also be due to factors such as improper isolation, improper manipulation of cement and heavy occlusal loads.

Keywords: Abfraction; Ceramic Chipping; Fixed Dental Prosthesis; Caries; Failure of Fixed Dental Prosthesis.

\section{Introduction}

Replacement of missing teeth in the oral cavity involves various treatment options like removable partial prosthesis, fixed dental prosthesis (fdps), and implants. Fixed partial dentures also known as fixed dental prosthesis have been a treatment modality for missing teeth from a long time [1]. The success of any restorations depends on the long term function, esthetics and comfort of the prosthesis $[2,3]$. The various reasons for failure of these prosthesis can be lack of marginal accuracy, caries of the abutment teeth, loss of a tooth posterior to the fpd having the need to intentionally replace the fpd, ceramic chipping [4, 5], dislodgement of the prosthesis, periodontal disease, periapical involvement, failed post retained crowns, poor esthetics, crown perforation etc [3]. These failures may be due to laboratory errors or due to errors during clinical procedures.

Abfraction is the pathological loss of tooth substance caused by biomechanical loading forces that result in flexure and failure of enamel and dentin at a location away from the loading. AF lesions present primarily at the cervical region of the dentition due to stress concentration at these areas and are typically wedge-shaped, with sharp internal and external line angles. These unbalanced forces may lead to excessive forces on the fixed partial denture in the oral cavity. There are various studies on the prevalence of failure of fixed dental prosthesis [6-8] however none of these studies have correlated the failure of the fdp with abfraction.

The reasons for failure of fixed partial prosthesis have been seen

*Corresponding Author:

Dr. Vinay,

Department of Prosthodontics, Saveetha Dental College and Hospitals, Saveetha Institute of Medical and Technical Sciences, Saveetha University, Chennai, 600077, India. Tel: 9176923110

E-mail: vinay.sdc@saveetha.com

Received: November 10, 2020

Accepted: December 15, 2020

Published: December 18, 2020

Citation: Rupawat Divya Kamlesh, Vinay. Prosthetic Re-Treatment Of Failed Fixed Dental Prosthesis Therapy and Its Correlation With Abfraction: A Retrospective Analysis. Int J Dentistry Oral Sci. 2020;7(12):1226-1230. doi: http://dx.doi.org/10.19070/2377-8075-20000242

Copyright: Vinay ${ }^{\circ} 2020$. This is an open-access article distributed under the terms of the Creative Commons Attribution License, which permits unrestricted use, distribution and reproduction in any medium, provided the original author and source are credited. 
overtime and hence knowledge regarding the clinical complications that can occur in fixed prosthodontics enhances the clinician's ability to complete a thorough diagnosis, strengthen their protocols to develop the most appropriate treatment plan [9]. It is important to establish evidence based dentistry. This study aims to evaluate the prosthetic re-treatment of failed fixed dental prosthesis therapy and its correlation with abfraction.

\section{Materials And Methods}

A retrospective study was done in a university based setting in Saveetha Dental College and Hospital, Chennai, India. Ethical clearance was obtained from the Institutional Ethical Committee (Ethical approval no. SDC/SIHEC/2020/DIASDATA/0619-0320). Data of 86000 patients between June 2019 and March 2020 were reviewed from the patients records and analysed that was documented in Saveetha Dental College and Hospital, Chennai, India. The study was based on a non probability consecutive sampling method. To minimize sampling bias, all case sheets of patients who were indicated for a fixed dental prosthesis were reviewed and included. Cross verification was done with the help of photographs and radiographic evidence.

Inclusion Criteria: Patient seeking retreatment of fixed dental prosthesis, any age group, both male and female.

Exclusion Criteria: Single crowns, Implant supported fixed partial dentures.

Data of 782 patients with failed fixed dental prosthesis was ana- lysed. Out of these 232 were retreatment cases and the reason for failure of fixed partial prosthesis patients was analysed. The data entered was tabulated and analysed for the prevalence of failure of fixed dental prosthesis and retreatment required due to posterior tooth loss, caries, esthetics, occlusal discrepancy, ceramic chipping and others. Data for the absence or presence of any teeth with abfraction in these patients was also tabulated. Statistical analysis was done using SPSS Statistics Software for windows, version 20.0 by IBM. Chi-square test was done to analyse the association of reason for failure of fdps with abfraction, age and gender.

\section{Results And Discussion}

Out of 582 , it was found that $14 \%$ of the cases had posterior tooth loss, $26 \%$ cases were repeated because of ceramic chipping, $21 \%$ cases came back with dislodgement of the fixed dental prosthesis, $6 \%$ of the cases had caries of the abutment tooth, 15\% cases showed some premature contacts or occlusal discrepancy, $18 \%$ of the cases were repeated because of esthetics (graph1).

Abfraction occurs due to improper occlusal load. This unbalanced occlusal load could be the one of the reasons for failure of fixed dental prosthesis.. There is a increased rate of ceramic chipping in the patients in whom abfraction is present, however the association between abfraction and failure of fdp is statistically not significant (Chi-square test, Pearson Chi-square value: 3.982, df: 3 , $p$ value $: 0.552$ ( $p>0.05$ which is statistically not significant) (table 1)(Graph 2). The association of age, presence or absence of abfraction and failure of fixed dental prosthesis showed no

Graph 1. Bar graph showing percentage distribution of the failures of fixed dental prosthesis. X-axis represents failure of the fdp and Y-axis represents the percentage of failed fixed dental prosthesis cases. The most prevalent is ceramic chipping-26\% (green color), followed by dislodgement-21\%, esthetics-18\% (yellow), occlusal discrepancy-15\%(grey), and posterior tooth loss-14\% (dark blue).

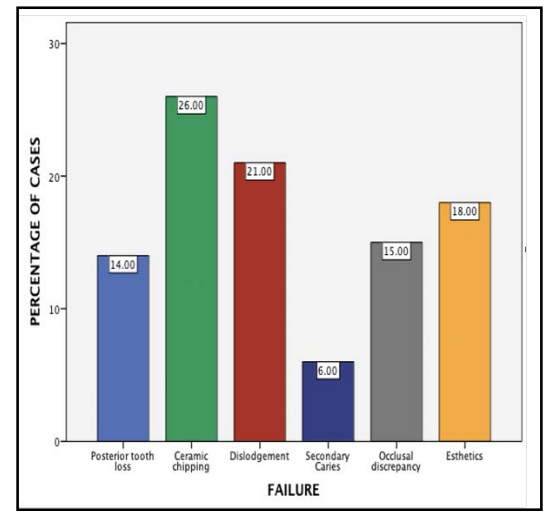

Table 1. Association between abfraction and failure of fixed dental prosthesis.

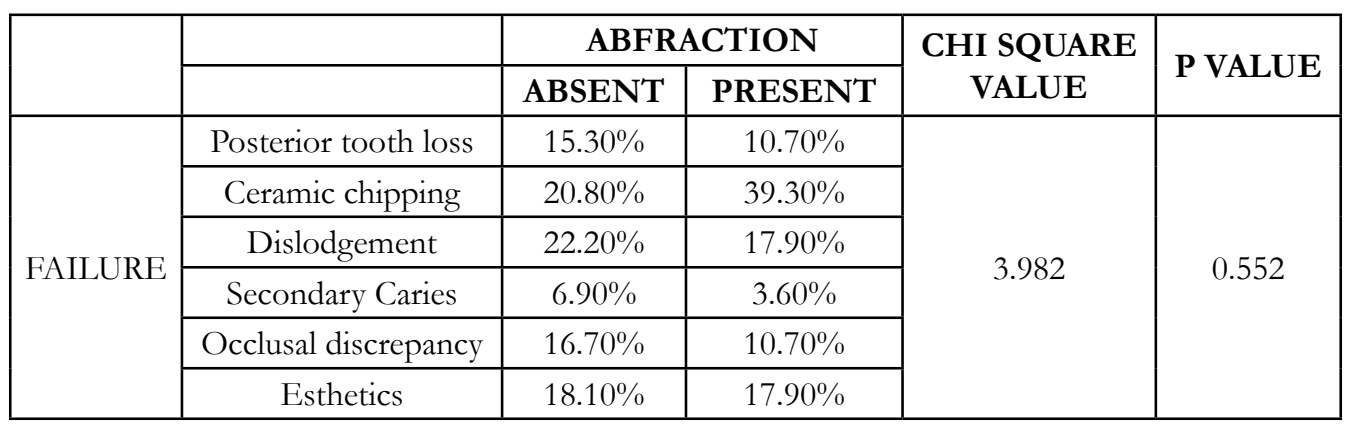

*The chi-square statistic is significant at the 0.05 level. 
Graph 2. Bar graph showing association between abfraction and failure of fixed prosthesis. X-axis represents the presence or absence of abfraction and Y-axis represents the percentage of failure associated with abfraction. There is an increased rate of ceramic chipping in the patients in whom abfraction is present, however the association between abfraction and failure of fdp it is statistically not significant (Chi-square test, Pearson Chi-square value: 3.982, df: 3, p value : 0.552 (p>0.05 which is statistically not significant).

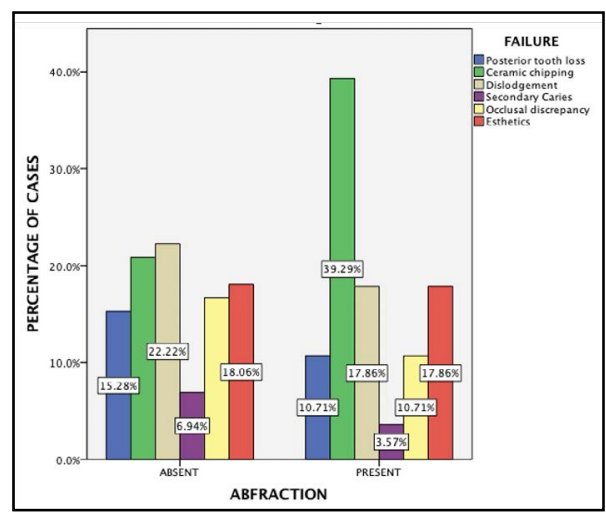

Table 2. Association between abfraction and failure of fixed dental prosthesis according to different age groups.

\begin{tabular}{|c|c|c|c|c|c|c|c|c|c|}
\hline & \multicolumn{4}{|c|}{ AGE } & \multirow{2}{*}{$\begin{array}{l}\text { CHI-SQUARE } \\
\text { VALUE }\end{array}$} & \multirow{2}{*}{$\begin{array}{c}\mathbf{P} \\
\text { VALUE }\end{array}$} \\
\hline & & & & $\begin{array}{l}18-30 \\
\text { years }\end{array}$ & $\begin{array}{l}31-50 \\
\text { years }\end{array}$ & $\begin{array}{l}51-70 \\
\text { years }\end{array}$ & $>71$ years & & \\
\hline \multirow{12}{*}{$\begin{array}{l}\text { AB- } \\
\text { FRAC- } \\
\text { TION }\end{array}$} & \multirow{6}{*}{ ABSENT } & \multirow{6}{*}{ FAILURE } & Posterior tooth loss & $5.30 \%$ & $13.50 \%$ & $38.50 \%$ & $0.00 \%$ & \multirow{6}{*}{22.18} & \multirow{6}{*}{0.103} \\
\hline & & & Ceramic chipping & $26.30 \%$ & $24.30 \%$ & $7.70 \%$ & $0.00 \%$ & & \\
\hline & & & Dislodgement & $21.10 \%$ & $24.30 \%$ & $23.10 \%$ & $0.00 \%$ & & \\
\hline & & & Secondary Caries & $10.50 \%$ & $5.40 \%$ & $7.70 \%$ & $0.00 \%$ & & \\
\hline & & & Occlusal discrepancy & $15.80 \%$ & $13.50 \%$ & $7.70 \%$ & $100.00 \%$ & & \\
\hline & & & Esthetics & $21.10 \%$ & $18.90 \%$ & $15.40 \%$ & $0.00 \%$ & & \\
\hline & \multirow{6}{*}{$\begin{array}{l}\text { PRE- } \\
\text { SENT }\end{array}$} & \multirow{6}{*}{ FAILURE } & Posterior tooth loss & $0.00 \%$ & $23.10 \%$ & $0.00 \%$ & $0.00 \%$ & \multirow{6}{*}{4.818} & \multirow{6}{*}{0.186} \\
\hline & & & Ceramic chipping & $50.00 \%$ & $23.10 \%$ & $85.70 \%$ & $0.00 \%$ & & \\
\hline & & & Dislodgement & $0.00 \%$ & $7.70 \%$ & $14.30 \%$ & $75.00 \%$ & & \\
\hline & & & Secondary Caries & $0.00 \%$ & $7.70 \%$ & $0.00 \%$ & $0.00 \%$ & & \\
\hline & & & Occlusal discrepancy & $25.00 \%$ & $7.70 \%$ & $0.00 \%$ & $25.00 \%$ & & \\
\hline & & & Esthetics & $25.00 \%$ & $30.80 \%$ & $0.00 \%$ & $0.00 \%$ & & \\
\hline
\end{tabular}

*The chi-square statistic is significant at the 0.05 level.

significant difference with Pearson Chi-square values of 22.180 and 4.818 respectively ( $p$ value $>0.05$ ) (table 2 ). The chi square value for association between gender, presence of abfraction and failure of fpd was 1.154 whereas that for gender, absence of abfraction and failure of fpd was 1.154 (table 3).

Fixed dental prosthesis remain an ideal treatment modality for middle-aged and older persons to retain a relatively high number of their teeth, due to economic reasons and in areas where bone length and width is insufficient to place implants [10-12]. They provide a psychological and social benefit of wearing a fixed rather than removable prosthesis [10]. However due to a variety of factors the practice of fixed prosthodontics may yield a certain percentage of unsatisfactory outcome which results in failures [13]. Dental caries was one of the reasons for failure of $\mathrm{fpd}$ in $6 \%$ of the cases. This may be because of poor marginal fit of prosthesis, marginal leakage as the cement in the margin areas dissolves leading to sensitivity. Open margins may occur due to clinicians' inability to detect the margins during cementation [14]. Other factors include high caries index mouth, poor oral hygiene maintenance etc., $[15,16]$. Similar studies in literature also showed caries as the reason for failure of fdps $[17,18]$.

Retreatment due to ceramic chipping was observed in $26 \%$ of the cases. This could be attributed to too much thickness of ceramic in combination with a thin finish line, technical issues like CTE mismatch,or if the prosthesis has gone through too many firing cycles leading to shrinkage of the ceramic making it weak under occlusal loads [19]. Failure of fdp due to ceramic chipping has also been documented in other studies [20-22]. Parafunctional habits like bruxism lead to excessive occlusal loads which may cause chipping on the ceramic. Dislodgement of prosthesis or loss of retention was observed in $21 \%$ of the retreatment cases. The studies conducted by Cheung [23], Karlsson in which the loss of retention was the primary cause of failure. The study conducted by Valderhaug shows similar results. If the tooth was not isolated properly before cementation, the cement interface can break leading to contamination of the cement from the oral fluids further causing dislodgement $[24,15]$. Poor resistance and retention form due to excessive taper of the abutment tooth could also 
Table 3. Association between abfraction and failure of fixed dental prosthesis according to different gender.

\begin{tabular}{|c|c|c|c|c|c|c|c|}
\hline & & & & \multicolumn{2}{|c|}{ GENDER } & \multirow{2}{*}{$\begin{array}{c}\text { CHI } \\
\text { SQUARE }\end{array}$} & \multirow[t]{2}{*}{ P VALUE } \\
\hline & & & & MALE & FEMALE & & \\
\hline \multirow{12}{*}{$\begin{array}{c}\text { AB- } \\
\text { FRAC- } \\
\text { TION }\end{array}$} & \multirow[t]{6}{*}{ ABSENT } & \multirow{6}{*}{$\begin{array}{l}\text { FAIL- } \\
\text { URE }\end{array}$} & Posterior tooth loss & $12.50 \%$ & $17.50 \%$ & \multirow[t]{6}{*}{3.397} & \multirow[t]{6}{*}{0.639} \\
\hline & & & Ceramic chipping & $18.80 \%$ & $22.50 \%$ & & \\
\hline & & & Dislodgement & $25.00 \%$ & $20.00 \%$ & & \\
\hline & & & Secondary Caries & $3.10 \%$ & $10.00 \%$ & & \\
\hline & & & Occlusal discrepancy & $15.60 \%$ & $17.50 \%$ & & \\
\hline & & & Esthetics & $25.00 \%$ & $12.50 \%$ & & \\
\hline & \multirow{6}{*}{$\begin{array}{l}\text { PRE- } \\
\text { SENT }\end{array}$} & \multirow{6}{*}{$\begin{array}{l}\text { FAIL- } \\
\text { URE }\end{array}$} & Posterior tooth loss & $12.50 \%$ & $10.00 \%$ & \multirow[t]{6}{*}{1.154} & \multirow[t]{6}{*}{0.949} \\
\hline & & & Ceramic chipping & $50.00 \%$ & $35.00 \%$ & & \\
\hline & & & Dislodgement & $12.50 \%$ & $20.00 \%$ & & \\
\hline & & & Secondary Caries & $0.00 \%$ & $5.00 \%$ & & \\
\hline & & & Occlusal discrepancy & $12.50 \%$ & $10.00 \%$ & & \\
\hline & & & Esthetics & $12.50 \%$ & $20.00 \%$ & & \\
\hline
\end{tabular}

*The chi-square statistic is significant at the 0.05 level

be one of the reasons for dislodgement and other complications [25].

Esthetics is the key to success of any restoration [26]. Among the retreatment cases $14 \%$ of the fixed dental prosthesis had been intentionally removed due to loss of posterior tooth in order to fabricate a new fdp. $18 \%$ were retreated due to esthetic failures. This could be due to a colour mismatch on the clinician's or the laboratory technician's part. Improper chair light, poor communication with the laboratory, improper white balance etc are few among the reasons.Among all the esthetic failure factors, unacceptable color match was greatest and was about $53.8 \%$ as reported in a study done by Chandranaik et al [27]. 15\% of the failure cases were due to occlusal discrepancy. This could be due to premature contact, high points on the restoration, unbalanced occlusal forces etc.

Limitation of our study is that it is done in an institutional setting, hence there are limited samples. As it is an institutional study there can be operator bias, protocol bias seen.It is important to find the causative factors which will help in the management of fdp failures [28]. This will help us to identify the condition of failure early and further complication [29] can be prevented so that the prognosis for the fdp is good.

\section{Conclusion}

Within the limitations of this study, it can be concluded that ceramic chipping is one of the common reasons for retreatment of fdps. Though presence of abfraction was seen in most cases of ceramic chipping, the failure of the fdps could also be due to factors such as improper isolation, improper manipulation of cement, heavy occlusal loads etc.

\section{Acknowledgement}

We would like to acknowledge Saveetha dental college and hospital for providing complete patient details required for the study purpose and their constant help and support for this research.

\section{References}

[1]. Jokstad A, Gökçe M, Hjortsjö C. A systematic review of the scientific documentation of fixed partial dentures made from fiber-reinforced polymer to replace missing teeth. International Journal of Prosthodontics. 2005 Nov $1 ; 18(6)$.

[2]. Jyothi S, Robin PK, Ganapathy D. Periodontal health status of three different groups wearing temporary partial denture. Research Journal of Pharmacy and Technology. 2017;10(12):4339-42.

[3]. Yamazaki S, Arakawa H, Maekawa K, Hara ES, Noda K, Minakuchi H, Sonoyama W, Matsuka Y, Kuboki T. A retrospective comparative ten-year study of cumulative survival rates of remaining teeth in large edentulism treated with implant-supported fixed partial dentures or removable partial dentures. Journal of prosthodontic research. 2013;57(3):156-61.

[4]. Selby A. Fixed prosthodontic failure. A review and discussion of important aspects. Australian dental journal. 1994 Jun;39(3):150-6.

[5]. Jain A, Ranganathan H, Ganapathy D. Cervical and incisal marginal discrepancy in ceramic laminate veneering materials: A SEM analysis [Internet]. Vol. 8, Contemporary Clinical Dentistry. 2017. p. 272.

[6]. Lovely M. Review of Fixed Partial Dentures [Internet]. 2006.

[7]. Sethi N. Fixed Partial Dentures [Internet]. Review of All Dental Subjects (ROADS). 2015. p. 519-519.

[8]. Research CM, Case Medical Research. Clinical Performance of Long-span Fixed Partial Dentures [Internet]. Case Medical Research. 2019.

[9]. Brägger U, Aeschlimann S, Bürgin W, Hämmerle CH, Lang NP. Biological and technical complications and failures with fixed partial dentures (FPD) on implants and teeth after four to five years of function. Clin Oral Implants Res. 2001 Feb;12(1):26-34. PubmedPMID: 11168268.

[10]. Näpänkangas R, Salonen-Kemppi MA, Raustia AM. Longevity of fixed metal ceramic bridge prostheses: a clinical follow-up study. J Oral Rehabil. 2002 Feb;29(2):140-5. PubmedPMID: 11856392.

[11]. Duraisamy R, Krishnan CS, Ramasubramanian H, Sampathkumar J, Mariappan S, NavarasampattiSivaprakasam A. Compatibility of Nonoriginal Abutments With Implants: Evaluation of Microgap at the Implant-Abutment Interface, With Original and Nonoriginal Abutments. Implant Dent. 2019 Jun;28(3):289-95.PubmedPMID: 31124826.

[12]. Ashok V, Nallaswamy D, Benazir Begum S, Nesappan T. Lip Bumper Prosthesis for an Acromegaly Patient: A Clinical Report. J Indian Prosthodont Soc. 2014 Dec;14(Suppl 1):279-82. PubmedPMID: 26199531.

[13]. Selvan SR, Ganapathy D. Efficacy of fifth generation cephalosporins against methicillin-resistant Staphylococcus aureus-A review. Research Journal of Pharmacy and Technology. 2016;9(10):1815-8.

[14]. Kannan A, Venugopalan S. A systematic review on the effect of use of impregnated retraction cords on gingiva. Research Journal of Pharmacy and 
Technology. 2018;11(5):2121-6.

[15]. Basha FY, Ganapathy D, Venugopalan S. Oral Hygiene Status among Pregnant Women. Research Journal of Pharmacy and Technology. 2018;11(7):3099-102.

[16]. Subasree S, Murthykumar K. Effect of Aloe Vera in Oral Health-A Review. Research Journal of Pharmacy and Technology. 2016;9(5):609-12.

[17]. Ashok V, Suvitha S. Awareness of all ceramic restoration in rural population. Research Journal of Pharmacy and Technology. 2016;9(10):1691-3.

[18]. Carlson BR, Yontchev E. Long-term observations of extensive fixed partial dentures on mandibular canine teeth. J Oral Rehabil. 1996 Mar;23(3):1639. PubmedPMID: 8667121.

[19]. Ganapathy D, Sathyamoorthy A, Ranganathan H, Murthykumar K. Effect of Resin Bonded Luting Agents Influencing Marginal Discrepancy in All Ceramic Complete Veneer Crowns. J ClinDiagn Res. 2016 Dec;10(12):ZC67ZC70. PubmedPMID: 28209008.

[20]. Borba M, Sonza QN, Della Bona A. Chipping behavior of ceramic restorations [Internet]. Vol. 29, Dental Materials. 2013. p. e5. Available from:

[21]. Petit F, Vandeneede V, Cambier F. Ceramic toughness assessment through edge chipping measurements-influence of interfacial friction. Journal of the European Ceramic Society. 2009 Aug 1;29(11):2135-41.

[22]. Broseghini C, Broseghini M, Gracis S, Vigolo P. Aesthetic functional area protection concept for prevention of ceramic chipping with zirconia frameworks. International Journal of Prosthodontics. 2014 Mar 1;27(2).
[23]. Cheung GS, Dimmer A, Mellor R, Gale M. A clinical evaluation of conventional bridgework. J Oral Rehabil. 1990 Mar;17(2):131-6. PubmedPMID: 2187970.

[24]. Ajay R, Suma K, Ali SA, Kumar Sivakumar JS, Rakshagan V, Devaki V, et al. Effect of Surface Modifications on the Retention of Cement-retained Implant Crowns under Fatigue Loads: An Study. J Pharm Bioallied Sci. 2017 Nov;9(Suppl 1):S154-60.PubmedPMID: 29284956.

[25]. Venugopalan S, Ariga P, Aggarwal P, Viswanath A. Magnetically retained silicone facial prosthesis. Niger J ClinPract. 2014 Mar;17(2):260-4.PubmedPMID: 24553044.

[26]. Jain AR, Nallaswamy D, Ariga P, Ganapathy DM. Determination of correlation of width of maxillary anterior teeth using extraoral and intraoral factors in Indian population: A systematic review. World J Dent. 2018 Jan;9:68-75.

[27]. Chandranaik MB, Thippanna RK. Fixed Partial Denture Failures: A Clinical Survey for Evaluation of the Factors Responsible [Internet]. Vol. 9. CODS Journal of Dentistry. 2017:41-5.

[28]. Kannan A. Effect of Coated Surfaces influencing Screw Loosening in Implants: A Systematic Review and Meta-analysis. World. 2017 Nov;8(6):496502.

[29]. Vijayalakshmi B, Ganapathy D. Medical management of cellulitis. Research Journal of Pharmacy and Technology. 2016;9(11):2067-70 